J. Lake Sci.(湖泊科学), 2016, 28(4): 818-824

DOI 10. 18307/2016. 0415

(c) 2016 by Journal of Lake Sciences

\title{
气温对太湖蓝藻复苏和休眠进程的影响
}

\author{
谢小萍, 李亚春 ${ }^{* *}$,杭 金金, 黄 珊 \\ (江苏省气象服务中心, 南京 210008)
}

\begin{abstract}
摘 要: 利用 2005-2014 年每日的卫星数据、气象站和浮标站观测资料研究复苏期和休眠期的平均气温、稳定通过界限 温度初终日、周有效积温与太湖蓝藻休眠和复苏时间的关系, 探讨气温是否是影响蓝藻休眠和复苏时间进程的关键因子. 分析结果显示: 太湖蓝藻复苏早晚与春季 ( $3-5$ 月) 气温密切相关, 春季气温越高, 蓝藻复苏时间越早; 太湖蓝藻休眠时间 与秋、冬季 (11-次年 1 月)气温密切相关, 秋、冬季气温越高, 蓝藻休眠时间越晚. 此外根据分析结果发现, 太湖首次出现 蓝藻水华的时间一般是气温稳定通过 $9^{\circ} \mathrm{C}$ 初日之后的 1 个月左右,但上一周期的休眠与下一周期的复苏之间气温异常偏 高会导致蓝藻水华首次出现时间早于稳定通过 $9^{\circ} \mathrm{C}$ 初日; 最后一次蓝藻水华出现时间与气温稳定通过 $4^{\circ} \mathrm{C}$ 的终日相近; 在 复苏期,湖水中的叶绿素 a 浓度随周有效积温变化而变化,二者相关系数为 0.9 .
\end{abstract}

关键词: 气温; 稳定通过界限温度; 积温;复苏;休眠;蓝藻;太湖

\section{The effect of air temperature on the process of cyanobacteria recruitment and dormancy in Lake Taihu}

\author{
XIE Xiaoping, LI Yachun ${ }^{* *}$, HANG Xin \& HUANG Shan \\ ( Jiangsu Meteorological Service Center, Nanjing 210008, P.R.China)
}

\begin{abstract}
To elucidate the effects of air temperature on the recruitment and dormancy processes of cyanobacterial blooms in Lake Taihu, the relationships between blooms events that retrieved by satellite images and the air temperature, the first date and last date for the daily temperature steadily passing through the threshold, as well as the weekly accumulated temperature are separately analyzed using the satellite data, meteorology data and buoy observation data during $2005-2014$. The analysis results show that: there is a significant negative correlation between the mean air temperature in spring and the onset time of cyanobacterial bloom, and the correlation coefficient is -0.85 ; the oneset time of cyanobacterial bloom is a month or so later than the air temperature steadily staying above $9^{\circ} \mathrm{C}$; there is a significant positive correlation between the mean air temperature from November to the next January and the dormancy time of cyanobacterial bloom, and the correlation coefficient is 0.85 ; the dormancy time of cyanobacterial bloom is close to the last date for the air temperature steadily staying above $4^{\circ} \mathrm{C}$; the concentrations of chlorophyll increase with weekly effective cumulative temperature during cyanobacterial recruitment period, and the correlation coefficient is 0.9 .
\end{abstract}

Keywords: Air temperature; air temperature stability passing through the threshold; accumulative temperature; cruitment; dormancy; cyanobacterial bloom; Lake Taihu

蓝藻是淡水湖泊中比较常见的一种浮游植物种类, 在适宜的气象条件和营养盐浓度下, 就会暴发性地 生长,形成蓝藻水华 ${ }^{[1]}$. 蓝藻水华已经成为当前最严重的水环境问题之一. 一般情况下, 营养盐是水华发生 的主要影响因子,但太湖中的平均氮、磷含量近年来一直居高不下,蓝藻水华发生已经成为常态. 孔繁翔 等 ${ }^{[2-3]}$ 研究发现太湖底泥中的内源营养盐足以支撑水华蓝藻的生长, 营养盐条件已不是太湖蓝藻生长的限 制因子,其它环境因素可能成为蓝藻生长与水华暴发的限制因子. Zhang 等 ${ }^{[4]}$ 的研究表明, 在蓝藻生长需要

* 江苏省基础研究计划太湖专项 (BK2007745)、江苏省科技支撑计划项目 (BE2011840)、江苏省气象局重点项目 (KZ201403) 和江苏省青年气象科研基金项目 (Q201413) 联合资助.2015-08-06 收稿;2015-11-04 收修改稿.谢 小萍(1983 ),女,博士, 高级工程师;E-mail:lucia129@126.com.

** 通信作者;E-mail: jsqxlyc@163.com. 
的营养物质充足的情况下, 气象条件就成为预测蓝藻水华形成的关键因子. 孔繁翔等 ${ }^{[2]}$ 将蓝藻水华的形成 分为相互区别而又连续的 4 个过程, 即休眠、复苏、生物量增加、上浮聚集,并认为影响每个阶段的主导环境 影响因子不同. 目前蓝藻复苏的概念是指在环境条件适合生长后, 底泥表面存活的蓝藻恢复生长并向水柱 迁移返回浮游状态的过程. 通常研究蓝藻复苏的方法是测定底泥和水体中藻类的生物量及其生长速度, 采 用菼光法 ${ }^{[5]}$ 、显微计数法 ${ }^{[6]}$ 、同位素法 ${ }^{[7]}$ 等方法通过野外原位实验或室内模拟实验开展研究. Cao 等 ${ }^{[8]}$ 在野 外利用自行设计的藻类捕捉器, 测定蓝藻复苏期间的色素含量, 并比较水柱和底泥中色素含量的变化, 结果 表明, 藻类的复苏与底泥环境中的温度密切相关; 在实验室中, 当水体温度达到 $14^{\circ} \mathrm{C}$ 时蓝藻开始少量进人水 柱中; 在太湖实地观测中, 蓝藻的复苏和进人水体都是在 $9^{\circ} \mathrm{C}$. 谭啸等 ${ }^{[9]}$ 采用逐步升温的方法培养梅梁湾冬 季泥样, 发现泥样中蓝藻的复苏温度略高于绿藻和硅藻的复苏温度, 但是复苏后蓝藻具有较高的比生长速 率, 有利于蓝藻确立优势而形成水华. 2007 年太湖发生的水危机事件是太湖富营养化的结果, 但当年冬、春 季气温异常偏高是关键诱因 ${ }^{[10]}$. 因此,温度可能是影响太湖蓝藻复苏进程的关键因子.

蓝藻下沉休眠即微囊藻下沉, 是胞内碳水化合物在低温下积累的结果. 不同水体中微囊藻的下沉临界 温度不同. Visser 等 ${ }^{[11]}$ 确定了 Nieuwe Meer 湖泊中的临界温度是 $14^{\circ} \mathrm{C}$; Abbots 池塘中微囊藻的临界温度是 $8 \sim 12^{\circ} \mathrm{C}^{[12]}$; Rostherne 湖中微囊藻的临界温度是 $9 \sim 11^{\circ} \mathrm{C}^{[13]}$; Hartbeespoort 水库中微囊藻的临界温度< $12.8^{\circ} \mathrm{C}^{[14]}$. 太湖的临界温度目前还没有确定.

虽然太湖蓝藻有复苏、生物量增加、上浮聚集、休眠的生长周期, 但每年太湖蓝藻复苏和休眠的时间都 不同. 以往的研究大多是基于实验室模拟或是几个月的实地观测开展, 难以做到长期监测太湖蓝藻复苏和 休眠的实际情况. 卫星遥感为获取多年太湖蓝藻复苏和休眠信息提供有效途径. 与以往的实验室模拟或短 期的实地观测不同, 本文根据 2005-2014 年的卫星监测结果和气象观测数据, 引人农业气象学中的稳定通 过界限温度初日和终日以及有效积温等指标, 分析在当前太湖水质富营养化的条件下气温对蓝藻的复苏和 休眠进程是否起关键作用.

\section{1 数据与方法}

\section{1 数据介绍}

卫星数据来源于风云卫星遥感数据服务网 ( http:// satellite.cma.gov.cn) 和江苏省气象服务中心存档的 20052014 年每日的 MODIS 卫星数据. 气象数据来源于江苏省 气象信息中心存档的国家基准气象站东山站 $\left(31.07^{\circ} \mathrm{N}\right.$, $\left.120.43^{\circ} \mathrm{E}\right)$ 逐日的气温、日照时数、降水量、气压和风速. 水 温数据来源于苏州气象局提供的上山村浮标站 $\left(31.32^{\circ} \mathrm{N}\right.$, $\left.120.28^{\circ} \mathrm{E}\right) 2014$ 年的观测数据, 其观测水深为 $0.5 \mathrm{~m}$. 叶绿 素 $\mathrm{a}$ 浓度数据来源于江苏省环境监测中心提供的兰山嘴 口东浮标站 $\left(31.21^{\circ} \mathrm{N}, 119.94^{\circ} \mathrm{E}\right) 2012$ 年 3-5 月的观测数 据, 其观测水深为 $0.5 \mathrm{~m}$. 气象站和浮标站的位置如图 1 .

\section{2 太湖蓝藻水华的反演方法}

由于覆盖有蓝藻水华的湖面与无藻湖面在可见光和 近红外波段都有较为明显差异 ${ }^{[15]}$, 尤其是在近红外波段, 有蓝藻水华覆盖的水体出现植被的 “陡坡效应”, 其反射 率明显高于无藻的清洁水体和浑浊水体, 因此利用近红外

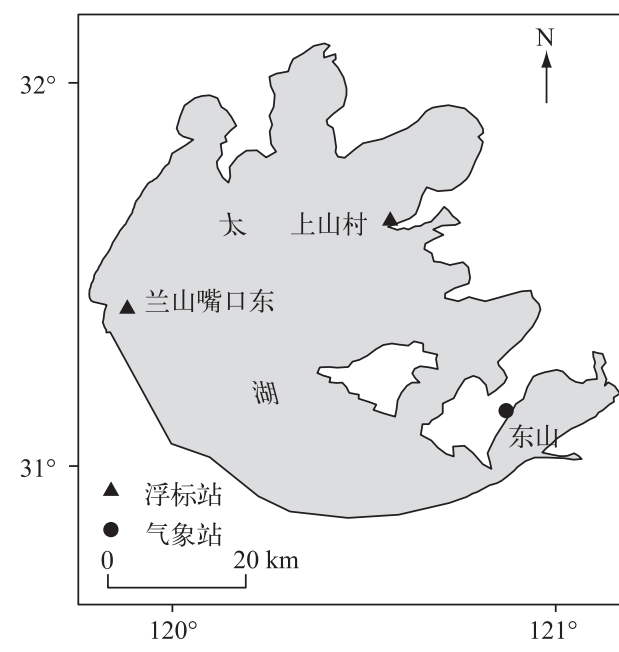

图 1 气象站和浮标站位置

Fig. 1 The location of weather station and buoy stations 波段和可见光波段生成的归一化植被指数 $(N D V I)$ 可以反映蓝藻水华信息 ${ }^{[16]} . N D V I$ 的计算公式为:

$$
N D V I=\frac{\rho_{\mathrm{NIR}}-\rho_{\mathrm{R}}}{\rho_{\mathrm{NIR}}+\rho_{\mathrm{R}}}
$$

式中, $\rho_{\mathrm{NIR}}$ 为近红外波段反射率, $\rho_{\mathrm{R}}$ 为红光波段反射率. 然后设定阈值, 大于阈值的区域即判定为蓝藻水华 覆盖区域. 阈值会根据观测时刻的大气状况、卫星天顶角结合目视识别在 $-0.15 \sim 0.10$ 之间进行调整. 


\section{3 有效积温和稳定通过界限温度的计算方法}

积温是 “某一时段内日平均气温对时间的积分” ${ }^{[17]}$, 用于研究作物生长、发育对热量的要求 ${ }^{[18]}$. 植物完 成某种发育进程需要具有一定温度条件的时间积累, 蓝藻完成复苏或休眠进程也可能需要一定温度条件的 时间积累, 因此本文引进积温来研究太湖蓝藻的生长进程中对热量的要求. 每种植物都有其生长的下限温 度, 当温度高于下限温度时, 它才能生长发育, 这个对植物生长发育起有效作用高出的温度值, 称作有效积 温. 根据前人的研究, 铜绿微囊藻在水温达到 $9^{\circ} \mathrm{C}$ 开始从湖底复苏进人水柱中 ${ }^{[8,19]}$, 这说明蓝藻也存在生长 的下限温度,因此本文引人有效积温来研究气温对蓝藻水华的影响. 有效积温的计算方法为:

$$
\sum_{P}^{M}\left(T-T_{1}\right)=K
$$

式中, $P$ 为开始时间, $M$ 为结束时间, $T$ 为每日平均气温, $T_{1}$ 为下限温度, $K$ 为有效积温.

农业气象上用稳定通过界限温度来指示作物生长和农事活动, 例如日平均气温稳定通过 $5^{\circ} \mathrm{C}$ 的初日表 示早春作物开始播种; 日平均气温稳定通过 $5^{\circ} \mathrm{C}$ 的终日表示作物生长开始变得缓慢, 作物叶子变化 ${ }^{[20]}$. 蓝藻 作为藻类植物, 也存在生长的下限温度和上限温度, 因此本文引进稳定通过界限温度的概念研究太湖蓝藻 进人复苏和休眠阶段的时间是否与稳定通过某界限温度相对应. 用五日滑动平均法计算稳定通过界限温度 的日期. 在 1 年中, 在任意连续 $5 \mathrm{~d}$ 的日平均温度平均值 $\geqslant$ 某界限温度的最长一段时期内, 在第 1 个 $5 \mathrm{~d}$ (即 上限) 中, 挑取最先一个日平均温度 $\geqslant$ 某界限温度的日期, 作为初日; 在最后 1 个 $5 \mathrm{~d}$ (即下限) 中, 挑取最末 一个日平均温度 $\geqslant$ 某界限温度的日期, 作为终 $\mathrm{日}^{[21]}$.

\section{2 结果和讨论}

\section{1 气温与水温的关系}

东山站的日均气温与上山村的日均水温全年变化趋势一致 (图 2), 统计得出二者的 Pearson 相关系数

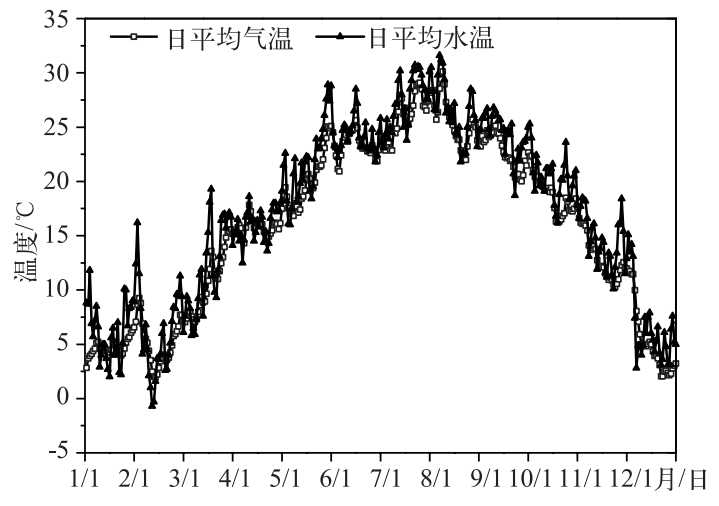

图 22014 年东山站日平均气温与 上山村日平均水温的对比

Fig. 2 Comparision of daily air temperature of Dongshan Station and daily water temperature in Shangshancun Station in 2014 为 0.98 , 通过 0.01 显著性检验, 这是因为太湖是一 个典型的浅水湖泊,其水温通常会根据气温的变化 快速响应 ${ }^{[22]}$.二者差值情况: 有 $86 \%$ 的 (315 d) 日平 均气温与水温的差值在 $3^{\circ} \mathrm{C}$ 以内, 其余 $14 \%(50 \mathrm{~d})$ 出现差值大于 $3^{\circ} \mathrm{C}$ 的日数是出现在气温突然明显 升高或突然明显下降的情况下, 这是由于水的比热 容远大于空气, 湖水的升温和降温会滞后于气温. 有 $77 \%(282 \mathrm{~d}$ ) 的日数是气温高于水温, 其余 $23 \%$ $(283 \mathrm{~d})$ 的日数水温高于气温是出现在冷空气来 临、气温突然下降的情况下. 全年日均气温和日均 水温的差值平均值为 $1.2^{\circ} \mathrm{C}$. 从上述统计分析结果 来看, 东山站的气温可以代表水温的变化趋势; 除 了气温骤升和骤降的情况, 大部分情况下日均气温 和日均水温数值相差不大; 除了冷空气来临情况, 通 常气温略高于水温. 由于缺少长时间序列的水温数 据, 而太湖的水温对气温能够快速响应, 因此在下面 的研究中用气温来分析蓝藻的复苏和休眠的关系.

\section{2 蓝藻复苏和休眠与平均气温的关系}

根据卫星监测结果, 2005-2014 年太湖蓝藻水华首次出现时间分布在 3-5 月, 其中出现在 4 月的有 7 年, 出现在 3 月的有 1 年,出现在 5 月的有 2 年. 2007 年蓝藻水华首次出现时间为近 10 年来最早,出现在 3 月 9 日, 当年的春季偏暖, 平均气温为近 10 年来最高, 为 $16.7^{\circ} \mathrm{C} .2010$ 年蓝藻水华首次出现时间为近 10 年 来最晚, 出现在 5 月 31 日, 当年春季偏冷, 平均气温也为近 10 年来最低, 为 $13.9^{\circ} \mathrm{C}$. 春季 $(3-5$ 月 )平均气温 与蓝藻水华首次出现时间存在显著的负相关 (图 3a), 二者的线性相关系数为 -0.85 , 通过 0.01 显著性检验, 
这说明近 10 年来由于营养盐的供应充足, 气温已成为影响太湖蓝藻复苏进程的关键因素. 春季气温越高, 蓝藻从底泥复苏进人水柱并上浮到水面的时间就越早.

根据卫星监测结果, 2005- 2014 年太湖蓝藻水华末次出现时间分布在 11 月一次年 1 月,其中有 1 年在 11 月,有 5 年在 12 月,有 4 年在次年 1 月. 2009 年蓝藻水华末次出现时间最早,为 11 月 24 日,当年 11 月一 次年 1 月的平均气温是 $6.5^{\circ} \mathrm{C}$, 为近 10 年来最低. 2009 年 11 月 13 日有明显的降温, 日平均气温从前一天的 $12.2^{\circ} \mathrm{C}$ 下降至 $5.1^{\circ} \mathrm{C}$, 至 11 月 18 日达到最低 $2.1^{\circ} \mathrm{C}$, 此外, 2009 年 11 月中旬的日平均气温为 $5.9^{\circ} \mathrm{C}$, 不及常年 $\left(1981-2010\right.$ 年) 同期平均气温 $\left(12.3^{\circ} \mathrm{C}\right)$ 的一半, 且后期 ( 11 月下旬 -12 月下旬) 也没有明显升温, 平均气 温较低. 11-1 月平均气温与蓝藻休眠时间存在显著正相关 (图 3b) , 二者的线性相关系数为 0.85 , 通过 0.01 显著性检验, 这说明气温越低,蓝藻休眠时间越早; 秋、冬季的气温是影响蓝藻休眠进程的主要因素.
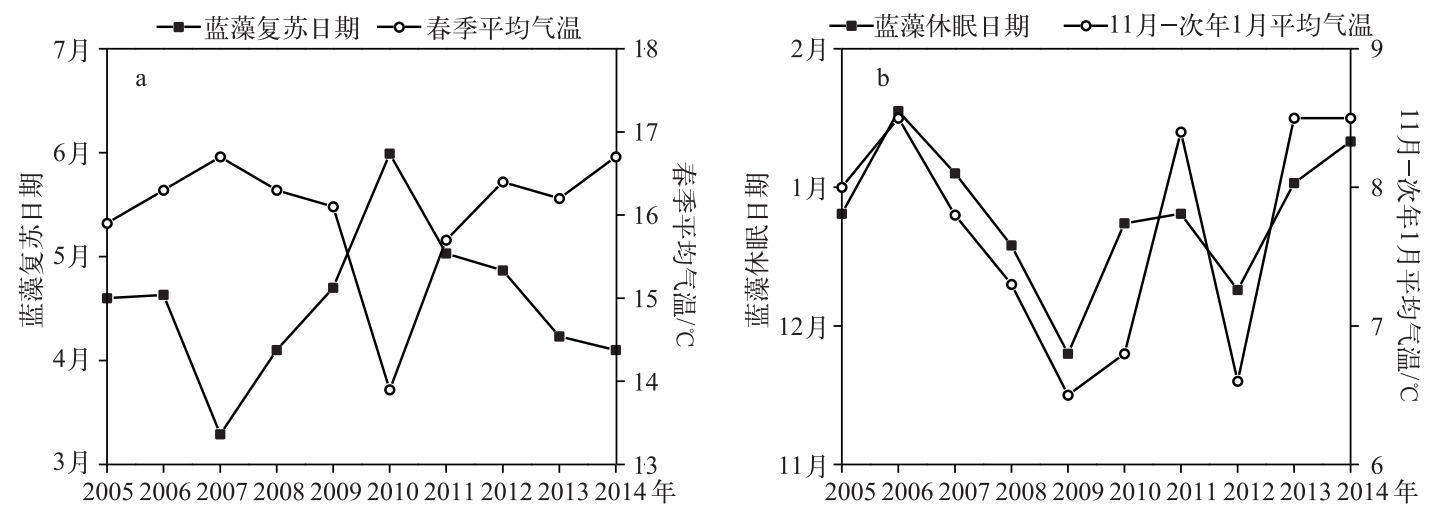

图 3 蓝藻首次和末次出现日期与平均气温的对比 ( $\mathrm{a}$ : 蓝藻水华首次出现日期与春季平均气温的 对比, $\mathrm{b}$ :蓝藻水华末次出现日期与 11 月一次年 1 月平均气温的对比)

Fig. 3 Comparision between the first and last date of cyanobacterial bloom and mean air temperature (a: Comparision of the first date of cyanobacterial bloom and spring mean air temperature, b: Comparision of the last date of cyanobacterial bloom and mean air temperature from November to the next January)

\section{3 蓝藻复苏和休眠与稳定通过界限温度的关系}

近 10 年来太湖蓝藻复苏时间基本晚于稳定通过 $9^{\circ} \mathrm{C}$ 的初日, 这与实地观测研究结果相符 ${ }^{[8]}$, 即太湖蓝 藻从 $9^{\circ} \mathrm{C}$ 开始进人水体. 太湖水温达到 $9^{\circ} \mathrm{C}$ 后, 蓝藻开始复苏生长, 达到一定数量后在气象和水文条件合适 的情况下,在水面聚集形成水华. 仅 2007 年因 2 月气温异常偏高, 3 月上旬又有一个小幅降温导致稳定通过 $9^{\circ} \mathrm{C}$ 初日晚于蓝藻水华首次出现日期. 一般情况下, 太湖蓝藻水华在气温稳定通过 $9^{\circ} \mathrm{C}$ 初日后 1 个月左右首 次出现.

计算稳定通过 $0 \sim 15^{\circ} \mathrm{C}$ 的初日和终日, 并与太湖蓝藻休眠和复苏时间对比, 发现稳定通过 $4^{\circ} \mathrm{C}$ 的终日与 蓝藻水华结束日数的变化趋势一致, 二者的相关系数为 0.87 , 通过 0.01 显著性检验; 另外, 稳定通过 $4^{\circ} \mathrm{C}$ 终日 与蓝藻水华结束日期相近,二者相隔时间在 $0 \sim 21 \mathrm{~d}$ 之间, 平均相隔天数为 $10.4 \mathrm{~d}$, 其中 2010 年稳定通过 $4^{\circ} \mathrm{C}$ 终日与蓝藻水华结束是同一天 (图 4). 2007-2010 年二者相隔天数都在 $10 \mathrm{~d}$ 以内, 因此可推断当太湖气温 下降到 $4^{\circ} \mathrm{C}$ 及以下, 蓝藻基本休眠.

近 10 年来,仅 2007 年蓝藻水华出现的时间早于稳定通过 $9^{\circ} \mathrm{C}$ 初日,为此下面单独分析 2007 年的气温 与蓝藻水华的关系. 根据 2007 年 1-3 月每日日平均气温与相应的蓝藻水华面积 (图 5), 可以看到 2007 年 1-3 月卫星监测到 4 次蓝藻水华,其中 1 月 17 日是上一轮蓝藻生长周期中还未休眠的蓝藻. 1 月 17 日之后 的 1 月日平均气温基本在 $5^{\circ} \mathrm{C}$ 上下略有波动, 蓝藻逐渐进人休眠越冬状态. 但进人 2 月气温开始急剧升高, 2 月 1-6 日一直处于气温不断上升状态, 2 月 6 日日平均气温达到 $14.1^{\circ} \mathrm{C}$, 此后除 3 月 5-8 日气温下降到 $7^{\circ} \mathrm{C}$ 以下, 其它时段气温大部分都保持在 $9^{\circ} \mathrm{C}$ 以上. 由于温度达到 $9^{\circ} \mathrm{C}$ 以上, 蓝藻会从底泥复苏迁移到水柱 中, 太湖蓝藻在 1 月下旬有短暂地休眠期之后进人 2 月就开始从底泥中迁移进人水柱中, 整个 2 月的温度条 

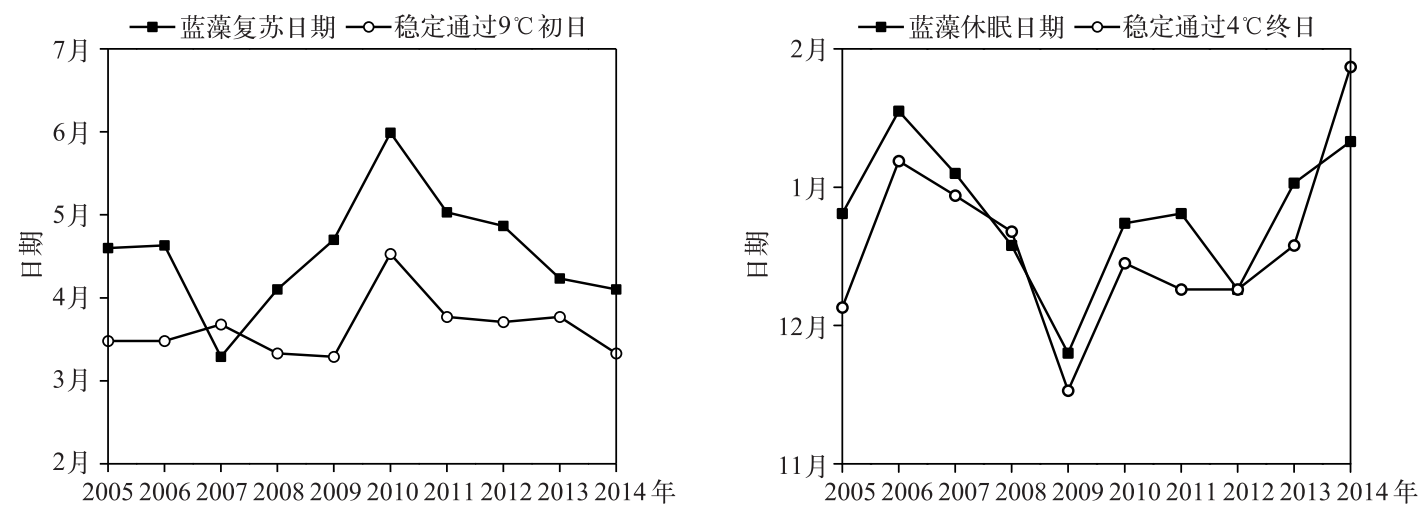

图 4 蓝藻水华复苏和休眠日期与稳定通过界限温度日期的对比 ( $\mathrm{a}$ : 蓝藻水华首次出现日数与稳定通过 $9^{\circ} \mathrm{C}$ 初日的对比, b: 蓝藻水华最后一次出现日期与稳定通过 $4^{\circ} \mathrm{C}$ 终日的对比)

Fig.4 Comparision of the first and last date of cyanobacterial bloom and the time of air temperature steadily staying above limited temperature (a:Comparision of the first date of cyanobacterial bloom and the oneset time of air temperature steadily staying above $9^{\circ} \mathrm{C}, \mathrm{b}$ : Comparision of the last date of cyanobacterial bloom and the end time of air temperature steadily staying above $4^{\circ} \mathrm{C}$ )

件都适宜蓝藻复苏迁移. 3 月气温继续升高, 蓝藻迁移到水柱中的量也增加. 2007 年 2 月的平均气温为 $9.4^{\circ} \mathrm{C}, 3$ 月下旬的平均气温为 $16.5^{\circ} \mathrm{C}$, 都为历年 ( 1960 年以来)气温最高的一年, 因此导致在 3 月 9 日有蓝藻 水华出现,面积为 $6 \mathrm{~km}^{2}, 3$ 月 25 日和 28 日有较大面积蓝藻水华出现, 面积分别为 40 和 $44 \mathrm{~km}^{2}$. 因此, 2007 年蓝藻水华出现时间明显早于其它年份是因为前一年的蓝藻还未完全下沉到底泥, 遇到 2 月份和 3 月下旬 气温异常偏高, 激发蓝藻活跃生长, 导致在 3 月下旬就有较大面积的蓝藻水华出现. 由于风速大于 $3 \mathrm{~m} / \mathrm{s}$, 就 会将蓝藻垂向混匀,在水表面难以见到成片的水华,因此将太湖区域的大风日 (风速 $>3 \mathrm{~m} / \mathrm{s}$ ) 的时间分布绘 制在图 5 的横坐标轴上. 每个月都有大风日, 大风日分布较分散, 其中 2 月大风日较少, 为 $9 \mathrm{~d}($ (图 5 ). 2 月蓝 藻处于从底泥向水柱复苏阶段, 水柱中的蓝藻数量在逐渐增多但还未达到形成蓝藻水华的量, 因此整个 2 月未监测到蓝藻水华. 3 月大风日较多, 有 $16 \mathrm{~d}$, 尤其是 3 月下旬, 卫星监测到成片蓝藻水华的 3 月 25 日和 28 日的日平均风速分别为 2.0 和 $2.3 \mathrm{~m} / \mathrm{s}$, 正好是在大风日的空档, 说明该时期水柱中蓝㩰数量已足够形成 蓝藻水华,只需适宜的风力条件湖面就会形成蓝藻水华.

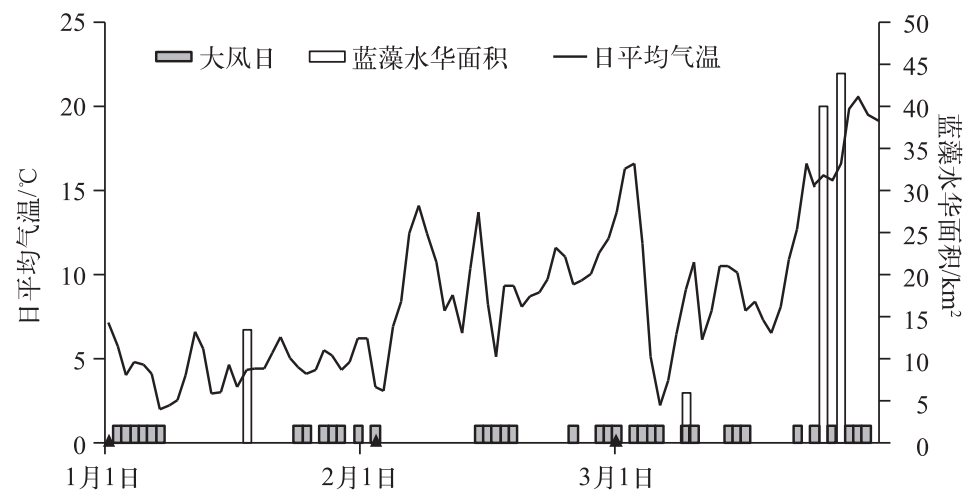

图 52007 年 1-3 月日平均气温与蓝藻水华面积的时间序列图

Fig.5 Time series graph of daily air temperature and cyanobacterial bloom area from January to March in 2007 


\section{4 有效积温与蓝藻复苏的关系}

通常在卫星监测到湖面有蓝藻水华聚集现象之前蓝藻 复苏过程就已开始, 当水温达到一定阈值, 蓝藻就进人水柱 中. 复苏期的温度是否影响蓝藻从底泥向水柱的迁移速度. 以 2012 年为例分析积温与蓝藻复苏的关系, 2012 年初次监 测到蓝藻水华的时间为 4 月 26 日. 根据 2012 年 3 月 1 日一 5 月 9 日太湖蓝藻水华卫星监测结果显示, 蓝藻水华主要分 布在西部沿岸区, 尤其是兰山嘴口东浮标所在区域附近出 现蓝藻水华频次较多, 因此统计 2012 年 3 月 1 日-5 月 9 日期间的周有效积温与兰山嘴口东浮标站叶绿素 $\mathrm{a}$ 周平均 浓度之间的关系. 统计发现 $9^{\circ} \mathrm{C}$ 以上的有效积温与叶绿素 a 浓度关系密切 (图 6), 二者呈显著正相关, 相关系数为 0.9 , 通过 0.01 显著性检验. 这说明在复苏期, 水中的叶绿素 a 浓 度随周有效积温变化而变化, 有效积温越高, 蓝藻从底泥向 水柱中转移量越大.

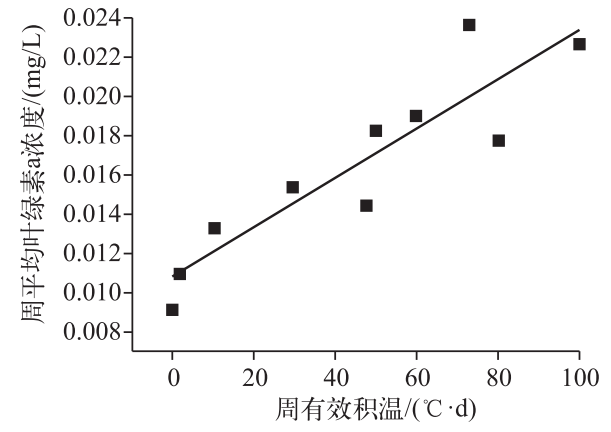

图 6 周平均叶绿素 a 浓度与 周有效积温 $\left(\geqslant 9^{\circ} \mathrm{C}\right)$ 的散点图

Fig.6 Scatter diagram of weekly mean chlorophyll-a concentration and weekly effective cumulative aire temperature $\left(\geqslant 9^{\circ} \mathrm{C}\right)$

\section{3 结论}

在太湖蓝藻复苏期, 气温越高, 蓝藻水华首次出现的时间就越早. 蓝藻在湖水达到 $9^{\circ} \mathrm{C}$ 时开始从底泥复 苏进人水柱中, 太湖湖面一般在气温稳定通过 $9^{\circ} \mathrm{C}$ 后 1 个月左右首次出现蓝藻水华,但 2007 年蓝藻水华首 次出现时间早于稳定通过 $9^{\circ} \mathrm{C}$ 初日,其原因是 2-3 月的异常高温导致上一周期的藻细胞没有完全下沉休眠 又进人下一周期的复苏上升. 在蓝藻复苏期, 湖水中的叶绿素 a 浓度会随着有效积温升高而增加. 虽然有大 风会暂缓蓝藻水华形成的时间,但从长期来看风力不是影响蓝藻复苏的主要因子.

在太湖蓝藻休眠期, 气温越低, 蓝藻休眠时间越早. 秋、冬季太湖气温逐渐降低, 蓝藻下沉到湖底, 导致 湖水中的蓝藻数量减少. 当低于 $4^{\circ} \mathrm{C}$ 以后, 湖水中的蓝藻数量降低到湖面不再能形成蓝藻水华, 蓝藻基本 休眠.

目前, 太湖水体中的营养盐供应量足够支持蓝藻生长, 易形成较严重的蓝藻水华, 因此深人研究气温对 太湖蓝藻复苏和休眠的影响, 对预测蓝藻水华并及时采取措施, 减缓蓝藻水华带来的危害具有理论和实际 应用意义.

致谢:感谢苏州市气象局和江苏省环境监测中心提供浮标观测资料.

\section{4 参考文献}

[ 1 ] Qin Boqiang, Wang Xiaodong, Tang Xiangming et al. Drinking water crisis caused by eutrophication and cyanobacterial bloom in Lake Taihu: Cause and measurement. Advances in Earth Science, 2007, 22(9) : 896-906( in Chinese with English abstract). [秦伯强, 王小冬, 汤祥明等. 太湖富营养化与蓝藻水华引起的饮用水危机一一原因与对策. 地球科 学进展, 2007, 22(9) : 896-906.]

[ 2 ] Kong Fanxiang, Gao Guang. Hypothesis on cyanobacteria bloom-forming mechanism in large shallow eutrophic lakes. Acta Ecologica Sinica, 2005, 25(3) : 589-595 (in Chinese with English abstract). [孔繁翔, 高光. 大型浅水富营养化湖泊 中蓝藻水华形成机理的思考. 生态学报, 2005, 25(3): 589-595.]

[ 3 ] Kong Fanxiang, Ma Ronghua, Gao Junfeng et al. The theory and practice of prevention, forecast and warning on cyanobacteria bloom in lake Taihu. J Lake Sci, 2009, 21(3) : 314-328( in Chinese with English abstract). DOI 10. 18307/2009. 0302. [ 孔繁翔, 马荣华, 高俊峰等. 太湖蓝藻水华的预防、预测和预警的理论与实践. 湖泊科学, 2009, 21 (3) : 314-328. ]

[ 4 ] Zhang M, Duan HT, Shi XL et al. Contributions of meteorology to the phenology of cyanobacterial blooms: Implications for future climate change. Water Research, 2012, 46(2) : 442-452.

[ 5 ] Tsai-yun L, Tsuzuki M, Takeuchi T et al. Quantitative determination of cyanobacteria in mixed phytoplankton assemblages 
by an in vivo fluorimetric method. Analytica Chimica ACTA, 1995, 302(1) : 81-87.

[ 6 ] Karlsson-elfgren I, Anna-kristina B. The importance of shallow sediments in the recruitment of Anabaena and Aphanizomenon (Cyanophyceae). Journal of Phycology, 2004, 40(5) : 831-836.

[ 7 ] Preston T, Stewart WP, Reynolds CS. Bloom-forming cyanobacterium Microcystis aeruginosa overwinters on sediment surface. Nature, 1980, 288: 365-367.

[ 8 ] Cao HS, Yi T, Kong FX et al. Relationship between temperature and cyanobacterial recruitment from sediments in laboratory and field studies. Journal of Freshwater Ecology, 2008, 23(3) : 405-412.

[ 9 ] Tan Xiao, Kong Fanxiang, Yu Yang et al. Effects of enhanced temperature on algae recruitment and phytoplankton community succession. China Environmental Science, 2009, 29(6): 578-582(in Chinese with English abstract). [谭啸, 孔繁 翔, 于洋等. 升温过程对藻类复苏和群落演替的影响. 中国环境科学, 2009, 29(6) : 578-582.]

[10] Xia Jian, Qian Peidong, Zhu Wei. Study on causes of early blue-green algae bloom in Lake Taihu in 2007. Journal of the Meteorological Science, 2009, 29(4) : 4531-4535(in Chinese with English abstract). DOI 10.3969/2012jms.00. [夏健, 钱培东, 朱玮. 2007 年太湖蓝藻水华提前暴发气象成因探讨. 气象科学, 2009,29(4)：4531-4535.]

[11] Visser PM, Ibelings BW, Mur LR. Autunmal sedimentation of Microcystis spp. as result of an increase in carbohydrate ballast at reduced temperature. Journal of Plankton Research, 1995, 17(5) : 919-933.

[12] Thomas RH, Walsby AE. Buoyancy regulation in a strain of Microcystis. Journal of General Microbiology, 1985, 131(4): 799-809.

[13] Reynolds CS, Rogers DA. Seasonal variations in the vertical distribution and buoyancy of Microcystis aeruginosa Kütz. emend. Elenkin in Rostherne Mere, England. Hydrobiologia, 1976, 48(1) : 17-23.

[14] Richard DR, Zohary T. Temperature effects on photosynthetic capacity, respiration, and growth rates of bloom-forming cyanobacteria. New Zealand Journal of Marine and Freshwater Resea, 1987, 21(3) : 391-399.

[15] Duan Hongtao, Zhang Shouxuan, Zhang Yuanzhi. Cyanobacteria bloom monitoring with remote sensing in Lake Taihu. $J$ Lake Sci, 2008, 20(2) : 145-152(in Chinese with English abstract). DOI 10.18307/2008.0202. [段洪涛, 张寿选, 张 渊智. 太湖蓝藻水华遥感监测方法. 湖泊科学, 2008, 20(2) : 145-152.]

[16] Wu Shengli, Liu Cheng, Sun Jun et al. Remote sensing and anlysis on meteorological factors of blue algal bloom in Lake Taihu. Meteorological Monthly, 2009, 35(1) : 18-23(in Chinese with English abstract). DOI 10.7519/j.issn.1000-0526. 2009.1.003. [武胜利, 刘诚, 孙军等.卫星遥感太湖蓝藻水华分布及其气象影响要素分析.气象, 2009, 35(1): 18-23. ]

[17] Zheng Dawei, Sun zhongfu. Discussion on scientificalness problem of accumulated temperature and its unit. Chinese Journal of Agrometeorology, 2010, 31(2) : 165-169(in Chinese with English abstract). DOI 10.3969/j. issn. 1000-6362.2010.02. 001. [郑大玮，孙忠富. 关于积温一词及其度量单位科学性问题的讨论. 中国农业气象, 2010, 31(2) : 165-169.]

[18] Gu Shuhong, Yan Xiaodong, Shi Yan et al. Analysis of characteristics of integrated temperature in each $1^{\circ} \mathrm{C}$ range in Guizhou. Chinese Jouranl of Agrometeorology, 2011, 32(4) : 521-524( in Chinese with English abstract). DOI 10.3969/j. issn.1000-6362.2011.04.007. [古书鸿, 严小冬, 石艳等. 贵州省温度界限内积温特征分析. 中国农业气象, 2011, $32(4)$ : 521-524. ]

[19] Latour D, Sabido O, Marie-josé S et al. Dynamics and metabolic activity of the benthic cyanobacterium Microcystis aeruginosa in the Grangent Reservoir (France). Journal of Plankton Research, 2004, 26(7) : 719-726.

[20] Song Shuihua, Song Liangluan. Determining initial and final date of steadily above the agricultural threshold temperature and its significance. Desert and Oasis Meteorology, 2009, 3(S1): 113-114(in Chinese with English abstract). [宋水华, 宋良娈. 界限温度初终日期的确定及意义. 沙漠与绿洲气象, 2009, 3(S1) : 113-114.]

[21] Wang Shuting. Statisitical methods of initial and final date of daily air temperature steadily above threshold temperature. Meteorological Monthly, 1982, 8(6) : 29-30 (in Chinese with English abstract). DOI 10.7519/j. issn.1000-0526.1982. 06.013. [王树廷. 关于日平均气温稳定通过各级界限温度初终日期的统计方法.气象, 1982, 8(6): 29-30.]

[22] Carpenter SR, Stuart GF, Nancy BG et al. Global change and freshwater ecosystems. Annual Review of Ecology and Systematics, 1992, 23: 119-139. 